With fuller information on the rare and unstable compounds, than is to be found in ordinary text books (such as "Miller's Elements"), no doubt numerous other instances might be noticed; these, however, will suffice to exemplify the general law.

With regard to black compounds, I have not included them in the above list, as they only complicate it unnecessarily; the urdinary term black being used to describe a very minute amount of any possible colour. It is only when the predominating colour is observed (as blue- olive- red-black, \&c.), that the description is of any value. "Brown" is likewise ill-defined in its spectral position, as various tints called brown generally include a small quantity of any colour except blue. Black and brown compounds are therefore inconclusive without a spectral examination of the colour in each case.

The real anomalies to the above law are the following compounds. $\mathrm{CrCl}_{2}$ white, $\mathrm{Cr}_{2} \mathrm{Cl}_{6}$ violet; $\mathrm{MnCl}_{2}$ pale pink, $\mathrm{MnCl}_{3}$ green brown; $\mathrm{As}_{2} \mathrm{~S}_{2}$ red, $\mathrm{As}_{2} \mathrm{~S}_{3}$ yellow; $\mathrm{HgCl}$ yellow white, $\mathrm{HgCl}_{3}$ white; AuI yellow, $\mathrm{AuI}_{3}$ green. In these five pairs the law is apparently reversed, but they cannot be said, to nullify an induction from thirty-five pairs, as enumerated above. A con. formity of six cases in seven to a rule is sufficient to establish it as a law, from which the modifying causes have not yet been eliminated.

One or two other cases might at first seem to be also exceptions; but as they are really salts, in which the electro-positive of the base is the same element as that of the acid, they are not necessarily to be compared with binary compounds.

In the order of the colours, it will be observed that, in numerous cases, white occurs between blue and yellow compounds; and there is oniy one instance of a violet compound with more of the electro-negative element than its white connection. As white light comes (in the natural arrangement) between blue and gellow, this order is more in accordance with the spectrum than is the order of metachromism announced by Mr. Ackroyd, in which white occurs before violet.

It may be worth notice that the electro-negative elements (whose increase reddens the compounds) are, on the whole, rather more red and yellow than the electro-positive, many of which are bluish, and even dark blue, as $\mathrm{Na}$.

This order of colours in successive compounds of a series (which might be called taxichromism) was observed by the writer some few years ago, in connection with the spectral order in metachromism; the latter, however, was only traced through a dozen or so, of the oxides, without pursuing the subject farther. Bromley, Kent W. M. Flinders Petrie

\section{Seasonal Order of Colour in Flowers}

I THINK it may be useful to mention, in reference to several letters on this subject in NATURE, that light appears to have no direct influence on the tints of flowers. I quote the following from Sachs's Textbook, Engl. transl., p. 675:-

"As long as sufficient quantities of assimilated material have been previously accumulated, or are produced by green leaves exposed to the light, flowers are developed even in continuous deep darkness which are of normal size, form, and colour, with perfect pollen and fertile ovules, ripening their fruits and producing seeds capable of germination."

$$
\text { W. T. THISELton Dyer }
$$

\section{Rainbow Projected on Blue Sky}

AN instance of this phenomenon, which is referred to as rare in NATURE (vol. vii. p. 68), occurred to-day, Feb. 22, 4.30 P.M. The sky was almost quite clear and a light shower of rain falling, caused one to look upwards for the clouds whence it proceeded, but the air was uniformly clear near the zenith, though bordering the horizon all round there were some detached cumuli, and a few thin filmy modifications higher in N.E. There were no visible signs of the origin of the falling drops. On turning round to east, a solar bow was seen, for the most part on a background of azure. It was a complete bow and moderately intense. Near the vertex it rested on thin clouds, as cid the extremities on the horizon, but they had no sensible effect on the phenomenon, for it was observed that as they receded from the upper portion, the bow remained intact and equally bright in all its parts. 'The arms spanned areas of blue sky. It was very transient, like the shower, and fading rapidly, was gone within Io sec. after it was first observed. At 4.45 P.M. , the left side of an incomplete bow was seen in N.E. on clcar sky, except at the lower extremity: no rain accompanied it. It was as evanescent as the first. The weather was very unsettled and showery with low barometer. Thermometer $50^{\circ}$, with brisk wind from W.S.W. $-3 \frac{1}{2}$ inches of rain had fallen during the previous 9 days.

Ashleydown, Bristol, Feb, 22

William F. Denning

\section{OUR ASTRONOMICAL COLUMN}

OLBERS' COMET OF 1815.-The comet discovered by Olbers, at Bremen, on March 6, 1815, and with which his name has been usually associated, belongs to the group, the members of which revolve in periods a few years less than the period of the planet Uranus. The deviation from parabolic motion was remarked independently a few months after the discovery by Bessel, Gauss, Olbers, Nicolai, and Triesnecker. Bessel calculated elliptic elements so early as the middle of May, and was followed by Gauss in June, and the former subsequently investigated, as completely as was practicable at the time, the elements resulting from the whole course of observation and the effect of perturbation in the actual revolution.

When first detected, the comet is said to have been barely visible in a good achromatic, and according to the $Z$ eit. schrift für Astronomie, was not discernible without telescopic aid at any time ; it is, however, upon record that in Russia it was seen with the naked eye. The last observation was made by Gauss at Göttingen, on August 25. At discovery on March 6, at ro P.M., it was in R.A. $49^{\circ} 3$ and N.P.D. $61^{\circ} 3$, distant from the sun $I^{\circ} 47$ and from the earth $\mathrm{I}^{\prime} 30$, and at Gauss's final observation it was in R.A. $217^{\circ}$ I, N.P.D. $84^{\circ} 5$, distant from the sun $2^{\circ}$ IO, and from the earth 2.36 . Representing the intensity of light at discovery (calculated according to the usual expression $\frac{I}{r^{2} \triangle^{2}}$ ) by unity, a maximum of $I^{\prime} 4$ was attained on May 3 , and it had diminished "on August 25 to $0^{*} 16$, or onesixth of that at discovery.

Bessel's determination of the elements of this comet and of the perturbations to the next return will be found in Abhandl. der Berl. "Acad. Mathem. Cl, I8I2-15. His definitive figures are as follow:-

Perihelion Passage, 1815, April 25.99867 M.T. at Paris.

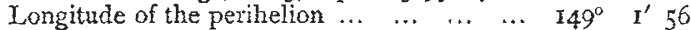
$\begin{array}{llllllll} & \text { " ascending node } \ldots & \ldots & \ldots & 83^{\circ} & 28^{\prime} & 34^{\prime \prime}\end{array}$

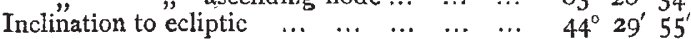
$\begin{array}{lllllllll}\text { Excentricity } & \ldots & \ldots & \ldots & \ldots & \ldots & \ldots & \ldots & 0.9312197\end{array}$ $\begin{array}{llllllll}\text { Semi-axis major } & \ldots & \ldots & \ldots & \ldots & \ldots & \ldots & 17 \cdot 63383\end{array}$

These elements apply to the date of perihelion pas sage; the longitudes from mean equinox of 1815 .

To the above value of the semi-axis corresponds a period of revolution of $74^{\circ} 049$ years. The distance in perihelion is $x^{\circ} 213$ (the earth's mean distance from the sun being taken as unity), and the aphelion distance 34.055 ; the minor semi-axis is found to be 6.427 . The ascending node is situate near the orbit of the planet Mars, and if the actual form of orbit is due to planetary attraction, it is probably to be ascribed to a near approach of the comet to Mars at some distant period. At the other node the radius-vector is $3.8 \mathrm{I}$ in the region of the minor planets. The comet, it will be seen, recedes beyond the orbit of Neptune, but near the aphelion it has a depression of nearly $40^{\circ}$ below the plane of the ecliptic.

According to Bessel, the mean motion at the instant of perihelion passage in 1815 corresponded to a period of revolution of $27046^{\circ} 9$ days, and he found that this would be diminished $824^{\circ} 5$ days by the united action of the planets Jupiter, Saturn, and Uranus, thus obtaining $26222^{\circ} 4$ days for the actual revolution, and fixing the next arrival at perihelion to 1887, February $9^{\circ} 4$. Beyond doubt, however, this date may now admit of a closer determination, and very probably we may soon hear of a further investigation being undertaken. The original observations made at the Observatory of Paris, and those at one or two other observatories in greater or less detail, are 